OPEN ACCESS

Check for updates

\section{State handgun purchase age minimums in the US and adolescent suicide rates: regression discontinuity and difference-in-differences analyses}

\author{
Julia Raifman, ${ }^{1}$ Elysia Larson, ${ }^{2}$ Colleen L Barry, ${ }^{3}$ Michael Siegel, ${ }^{4}$ Michael Ulrich, ${ }^{4}$ \\ Anita Knopov, ${ }^{5}$ Sandro Galea ${ }^{4}$
}

${ }^{1}$ Department of Health Law,
Policy, and Management,

Policy, and Management,

Public Health, Boston, MA

${ }^{2}$ Harvard TH Chan School of Public Health, Boston, MA, USA

${ }^{3}$ Johns Hopkins Bloomberg School of Public Health,

Baltimore, MD, USA

${ }^{4}$ Boston University School of Public Health, Boston, MA, USA ${ }^{5}$ Brown University Department of Emergency Medicine,

Providence, RI, USA

Correspondence to: J Raifman jraifman@bu.edu

(or @juliaraifman on Twitter ORCID 0000-0001-6968-658X)

Additional material is published online only. To view please visit the journal online.

Cite this as: $B M J$ 2020;370:m2436

Accepted: 1 June 2020
02118, USA http://dx.doi.org/10.1136/bmi.m2436

\section{ABSTRACT}

OBJECTIVE

To evaluate the association between US state policies that establish age 18 or 21 years as the minimum purchaser age for the sale of handguns and adolescent suicide rate.

\section{DESIGN}

Regression discontinuity and difference-in-differences analyses.

SETTING

46 US states without policy changes between 2001 and 2017; Missouri and South Carolina, which lowered the age for handgun sales in 2007 and 2008, respectively; and West Virginia and Wyoming, which increased the age for handgun sales in 2010.

\section{PARTICIPANTS}

Adolescents aged 13 to 20 years(554 461961

from 2001 to 2017) in the regression discontinuity analysis, and adolescents aged 18 to 20 years (168934041 from 2002 to 2014) in the main difference-in-differences analysis.

\section{MAIN OUTCOME MEASURE}

Suicide rate per 100000 adolescents.

RESULTS

In the regression discontinuity analysis, state policies that limited the sale of handguns to those aged 18 or older (relative to 21 or older) were associated with an increase in suicide rate among adolescents aged 18 to 20 years equivalent to 344 additional suicides

\section{WHAT'S ALREADY KNOWN ON THIS TOPIC}

Firearms are a particularly lethal means of suicide attempts

Access to firearms is associated with suicide for the general population and for adolescents

A study based on suicide data from 1976 to 2001 found that policies restricting the sale of handguns to those aged 21 or older were associated with reductions in firearm related suicides but not overall suicides among adolescents aged 18 to 20 years

\section{WHAT THIS STUDY ADDS}

In a regression discontinuity analysis, restricting the sale of handguns to purchasers aged 18 years or older, relative to 21 years or older, was associated with an increased suicide rate among adolescents aged 18 to 20 years In a difference-in-differences analysis, lowering the age minimum for handgun purchases from 21 to 18 years was associated with an increase in the suicide rate among adolescents aged 18 to 20 years in two states

Increasing the age of handgun purchases from 18 to 21 years was not associated with a change in the suicide rate in two states with high levels of household firearm ownership in each state where they were in place between 2001 and 2017. In the difference-in-differences analysis, state policies that limited the sale of handguns to those aged 21 or older were associated with 1.91 fewer suicides per 100000 adolescents aged 18 to 20 years ( $95 \%$ confidence interval -3.13 to -0.70 , permutation adjusted $\mathrm{P}=0.025$ ). In the difference-indifferences analysis, there were 1.83 fewer firearm related suicides per 100000 adolescents $(-2.66$ to -1.00 , permutation adjusted $P=0.002$ ), with no association between age 21 handgun sales policies and non-firearm related suicides. Separate event study estimates indicated increases in suicide rates in states that lowered the age of handgun sales, with no association in states that increased the age of handgun sales.

\section{CONCLUSIONS}

A clear discontinuity was shown in the suicide rate by age at age 18 in states that limited the sale of handguns to individuals aged 18 or older. State policies to limit the sale of handguns to individuals aged 21 or older were associated with a reduction in suicide rates among adolescents. Increases in suicide rates were observed after states lowered the age of handgun sales, but no effect was found in states that increased the age of handgun sales.

\section{Introduction}

More than 48000 suicides occurred in the United States in 2018; an increase in the suicide rates for the 10th consecutive year both overall and among adolescents. ${ }^{1}$ Suicide is a particular concern in adolescents as it is the second most common cause of death in this age group after unintentional injuries. ${ }^{2}$ Firearms account for more than half of the deaths from suicide in the US. ${ }^{3}$

Firearms are common in US households, with $41 \%$ of Americans reporting living in a household with a gun in $2017 .{ }^{4}$ Firearms are a particularly lethal method of suicide attempts, ${ }^{5}$ and access to firearms is associated with increased deaths from suicide. ${ }^{6-8}$ Firearm purchases have been specifically related to suicideone study found the risk of suicide by firearms to be 57 times greater among Californians who had purchased a handgun in the past week compared with that in the general population of adults in the state. ${ }^{9}$ Though few changes have occurred in most state firearm policies in recent years, changing the legal age at which handguns can be purchased has been politically feasible; since 2018, three states increased the minimum age of handgun purchase..$^{10-12}$ We investigated the relation between the minimum age of handgun purchase in US states and suicide among adolescents. 
A 1968 US federal law required that licensed firearms dealers only sell handguns to those aged 21 or older, but it did not impose a minimum purchaser age on unlicensed sales. The 1994 Brady Handgun Violence Prevention $\mathrm{Act}^{13}$ limited all firearm sales across the US to purchasers aged 18 years or older. By June 2020, 17 states had policies requiring the sale of unlicensed handguns be limited to individuals aged 21 or older; the other 33 states continued to permit unlicensed sales to those aged 18 to 20 years. ${ }^{14}$ Federal policy permits the sellers of firearms to be unlicensed if they do not regularly sell firearms for profit, without defining regular sales. ${ }^{15}$

Little evidence exists about whether policies for limiting handgun sales to those aged 21 or older are associated with deaths from suicide, particularly since the introduction of the 1994 Brady act. One study evaluated the link between suicides and laws for minimum purchase age passed in 29 states between 1976 and 2001 and found that the policies for limiting handgun sales to those aged 21 or older were associated with statistically significant reductions in firearm related suicides but not in overall suicides. ${ }^{16}$ This study was based on a difference-in-differences design but did not examine pre-period trends in all cause suicide to assess the suitability of the comparison group. We conducted an analysis based on more recent data most relevant to the current policy environment, including a difference-in-differences analysis in which we evaluated parallel trends.

We estimated the impact of policies to restrict the sale of handguns to those aged 21 or older on suicide rates in adolescents. We used two methods for analyzing observational data: a regression discontinuity approach to evaluate whether suicide rates among adolescents aged 18 to 20 diverged from age trends in suicide rates among adolescents aged 13 to 17 when states limited handgun purchases to those aged 18 or older relative to aged 21 or older; and a differencein-differences approach to compare temporal trends in the suicide rate in states that changed policies relative to all other states. We conducted difference-indifferences analyses based on two states that rescinded the age 21 minimum and two states that implemented the age 21 minimum.

\section{Methods \\ Sample}

We obtained data on suicide rates by state and age from 1999 to $2018 .^{3}$ For the regression discontinuity analysis, we excluded states with policy changes. To include as many states as possible, we used data from 2001 to 2017 (two states changed policies in 2018 and two states changed policies between 1999 and 2001). We included the full population of adolescents aged 13 to 20 years in all 46 US states that did not change their policies between 2001 and 2017. Four states-Missouri, South Carolina, West Virginia, and Wyoming-implemented policy changes between 2001 and 2017 and were therefore excluded. ${ }^{1417}$
For the difference-in-differences analyses, we determined that Missouri, South Carolina, West Virginia, and Wyoming implemented policy changes between 2004 and 2013, the period that allowed for at least five years of data before and after each state policy change. The sample was the full US population of adolescents aged 18 to 20 years from 2002 to 2014 , the period five years preceding and five years following policy changes in the four intervention states (policy changes occurred between 2007 and 2010).

\section{Data}

The main exposure of interest for the regression discontinuity analysis was being aged 18 to 20 years old in a state with a policy that limited handgun sales to purchasers aged 18 or older (versus aged 21 or older). From the State Firearms Law Database ${ }^{14}$ and the Giffords Center law database ${ }^{17}$ we determined that the minimum age for handgun purchasers throughout the study period was 18 years in 34 states and 21 years in 12 states. The two databases had consistent information on state handgun purchaser age, with the exception of Illinois, where adolescents aged 18 to 20 years can purchase a handgun with parental permission; we considered Illinois to have a minimum purchaser age of 18 years. We weighted data based on the size of the state population aged 13 to 20 years.

The main exposure of interest for the differencein-differences analysis was a policy change in the minimum purchaser age for handgun sales. In August 2007, Missouri implemented a policy to reduce the minimum purchaser age from 21 to 18 years, when it repealed the Missouri Revised Statutes Section 571.090. In the same year, Missouri rescinded its policy requiring a permit and background check to purchase handguns. In April 2008, South Carolina implemented the 2008 South Carolina Laws Act 192 (H.B. 4364), reducing the minimum purchaser age from 21 to 18 years. In contrast, in 2010, West Virginia amended Section 61-7-10 of the Code of West Virginia, restricting unlicensed firearm sales to the licensed firearm sales age, thereby limiting handgun sales to purchasers aged 21 years or older. In March 2010, Wyoming increased the minimum age of handgun purchase from 18 to 21 years with the Wyoming Firearms Freedom Act. ${ }^{18}$ We considered the policy change period to begin in the calendar year of policy implementation in each state.

The main outcomes were suicide rate by age (regression discontinuity analysis) or by year (difference-in-differences analysis). From the National Vital Statistics System, we obtained cause specific and intent specific suicide data for the full US population in the relevant age group, with deaths classified using ICD-10 codes (international classification of diseases, 10th revision). We used US Census data on population size by age, state, and year drawn from the Webbased Injury Statistics Query And Reporting System (WISQARS). ${ }^{3}$ From this same system we also calculated covariate data on population density and demographic characteristics. 


\section{Analysis}

In the regression discontinuity analysis, we described population characteristics in states with age 18 relative to age 21 handgun sales policies and among those younger (ages 13 to 17) and older (ages 18 to 20) than the age 18 threshold. We used a modified regression discontinuity approach ${ }^{1920}$ based on the discontinuity in access to firearms when people reached the age of 18 years in states with a minimum handgun purchaser age of 18 years. The premise is that adolescents just above and just below age 18 years have similar characteristics but differ in their access to firearms when the age of handgun purchase is 18 years; we evaluated whether the adolescent populations above and below the threshold had similar characteristics by comparing the ethnicity/race of the adolescent populations aged 13 to 17 and aged 18 to 20 in each policy group. We extended the typical regression discontinuity analysis by using states with a minimum handgun purchaser age of 21 years as a comparison group. To account for overdispersion, we estimated negative binomial regression models, with total suicides as the outcome and log population as an offset (appendix equations 1 and 2). The main indicators of interest were a binary indicator for being aged 18 to 20 years in a state with a minimum handgun purchaser age of 18 years and a term interacting this binary indicator with continuous age. We also adjusted for age and a second order polynomial for age. We estimated the number of suicides that would be averted with a minimum handgun purchaser age of 21 years, by computing and summing the predicted probabilities of suicide at each age between 18 and 20 years in states with an age 18 relative to age 21 handgun purchaser minimum. Trends in suicide rates by age are depicted graphically by minimum age of handgun sales for all states without policy changes from 2001 to 2017 and for the intervention states during the five years prior to and following policy changes. In a sensitivity analysis, we estimated a model that allowed for differing age trends in states with different policies through terms interacting continuous age and age squared with the policy group.

In the difference-in-differences approach ${ }^{21} 22$ we compared changes in suicide rates before and after policy changes with changes in the suicide rates over time in comparison states. As a first step, we compared population characteristics in intervention and comparison states.

An important assumption in difference-indifferences analyses is that there would be parallel trends in the outcome in intervention states and comparison states in the absence of any intervention; parallel trends in the pre-period suggest there would have been parallel trends in the post-period in the absence of a policy change. We tested for parallel trends by evaluating whether there were differences in temporal trends in suicide rates in intervention relative to comparison states before policy changes. The main regression analysis was repeated for the period before policy changes, interacting time in years with being in an intervention state. Separate parallel trends tests were conducted on the states that decreased the age minimum age of handgun purchasers from 21 to 18 years in 2007 and 2008 and for the states that increased the age minimum from 18 to 21 years in 2010. We also repeated the main analysis as separate event study models ${ }^{23}$ for states that decreased or increased the minimum age of handgun purchasers. In the event study models, we replaced the binary policy indicator with binary indicators for living in intervention states in a series of two year periods before and after policy changes. The reference group was being in a comparison state or being in an intervention state in the two year period before the policy change.

For the main difference-in-differences analysis, we estimated a linear regression model, with the rate of suicides per 100000 adolescents as the outcome for total and for firearm and non-firearm related suicides to determine if changes in firearm related suicides drove changes in total suicides. We chose a linear regression model based on evidence that maximum likelihood models underestimate standard errors in the presence of fixed effects. ${ }^{25}$ The main indicator of interest was living in a policy change state during the period when handgun sales were restricted to those aged 21 or older. We included state and year fixed effects that controlled for each state and year and that capture any time invariant state characteristics, such as geography and the minimum age for handgun purchases in neighboring states. We adjusted for state characteristics that changed over time, including the proportion of firearm related suicide deaths in adults, population density, and the proportion of the population that was white or Native American. We adjusted for changes in state background check policies ${ }^{2627}$ and handgun permit to purchase policies ${ }^{28}$ as documented in the State Firearms Law Database ${ }^{14}$ and the Giffords Center law database. ${ }^{17}$ We did not adjust for policies requiring locked storage of firearms because no states changed this policy during the study period. We know of no other policy changes that would have differentially affected suicides in intervention relative to comparison states. We weighted the analysis by the proportion of all adolescents aged 18 to 20 years who lived in each state in each year and clustered standard errors by state to account for serial autocorrelation. ${ }^{29}$

Difference-in-differences models with a small number of groups can lead to underestimation of standard errors. ${ }^{30}$ To precisely estimate the $\mathrm{P}$ value of the main analysis, we ran 1000 permutations of the main analyses, randomly assigning states to "placebo" policy changes in the years when intervention states actually changed policies. Based on the distribution of $t$ statistics from this analysis, we calculated the likelihood of observing a $t$ statistic with an absolute value greater than that estimated in the main analysis. We calculated the per cent reduction in suicides relative to the mean rate in all states before 2007, when Missouri was the first study state with a policy change. We estimated the number of deaths that would 
be averted with handgun sales limited to purchasers with a minimum age of 21 relative to 18 in the 33 states with an age 18 minimum in March 2020 based on the most recent, 2018 data on the number of adolescents aged 18 to 20 years in each state.

To explore effect heterogeneity and further evaluate the parallel trends assumption, we repeated the main analysis with a term interacting the policy change with a binary indicator for increasing, relative to decreasing, the age of handgun sales. We also evaluated heterogeneity based on the separate event study models for states that decreased or increased the age of handgun sales. ${ }^{23}{ }^{24}$ Finally, we graphed estimates of the total and cause specific suicide fatality rate during the five years preceding and following policy changes in each intervention state and during the corresponding period in the 46 comparison states.

We conducted several difference-in-differences sensitivity analyses. To ensure the analysis was not sensitive to functional form, we repeated the analysis as a negative binomial regression, with total suicide deaths as the outcome and log population as the offset. To evaluate whether those not exposed to policy changes experienced changes in suicide rates, we repeated the main analysis among those aged 13 to 17 years. To evaluate alternative comparison groups, we estimated the effects of the policy changes relative to synthetic control states separately for the two states that changed the minimum age for handgun purchases from 21 to 18 years and from 18 to 21 years using the synth_runner package in Stata 15. The synthetic controls were generated from the subset of states with the same policies before intervention state policy changes. We estimated the deaths averted by multiplying annual effect estimates by state population size. ${ }^{31}$ Finally, to ensure the analysis was not sensitive to the period in which the study was conducted, we repeated the main analysis separately over four years and over six years before and after policy changes.

Patient and public involvement

Patients and the public were not involved in this study.

\section{Results}

In the regression discontinuity analysis, the race/ ethnicity of the population of adolescents older and younger than 18 years was similar (table 1), although the large population size meant that differences of less than 0.1 percentage points were statistically significant. Adolescents in states that limited the sale of handguns to those older than 21 years were more likely to be Asian or Pacific Islanders than those in states that limited the sale to age 18 and older. States with age 21 limits had lower firearm ownership in 2004 (24\% v 43\%) and were more population dense (400 $v 89$ people per square mile (154 v 34 per square kilometer)).

In the regression discontinuity analysis, a discontinuity was found in the suicide rate (incident rate ratio $1.26,95 \%$ confidence interval 1.10 to 1.45 ) and the slope of increases in the suicide rate with age
$(1.09,1.03$ to 1.16$)$ at age 18 in states with age 18 handgun sales policies (fig 1 and table 2). Based on the predicted probabilities of suicide at ages 18 to 20, an average of 344 adolescent suicide deaths would have been averted in each state with a minimum handgun purchaser age of 21 compared with age 18 from 2001 to 2017. In the sensitivity analysis that allowed for differing age trends in states with a minimum handgun purchaser age of 18 or age 21 , the main effect estimates were consistent for the increase in the suicide rate at age $18(1.19,1.10$ to 1.28$)$ and the increase in the slope of the increase in the rate $(1.23,1.14$ to 1.32$)$; based on the predicted probabilities of suicide in this analysis, an estimated 406 deaths would have been averted with a minimum handgun purchaser age of 21 compared with age 18.

In the difference-in-differences analysis, the characteristics of adolescents in the intervention states differed from those in the comparison states (table 3). In particular, comparison states had greater population density and lower firearm ownership, and a greater share of the adolescent population was Asian or Pacific Islander. Household firearm ownership was particularly high in Wyoming (66\%) and West Virginia (59\%) relative to comparison states (38\%), and population density was particularly low in Wyoming relative to comparison states (5 $v 170$ people per square mile ( $2 v 65$ people per square kilometer)).

The event studies show that temporal trends in suicide rates in intervention states (Missouri, South Carolina, West Virginia, and Wyoming) relative to comparison states were characterized by fluctuations but were relatively parallel to trends in comparison states before policy changes (fig 2). The tests for parallel trends also indicated that temporal trends in suicide rates did not differ in Missouri and South Carolina (which decreased the minimum age of handgun purchase) relative to comparison states for total (0.02 suicides per 100000 adolescents per year, 95\% confidence interval -0.57 to 0.61 , appendix table 2 ) or cause specific suicides (firearms: 0.03 suicides per 100000 adolescents per year, -0.42 to 0.47 ; non-firearms: fewer than -0.01 suicides per 100000 adolescents per year, -0.28 to $0.27)$. Although there were no statistically significant differences in the trends in the total suicide rate $(-0.91$ suicides per 100000 adolescents per year, -2.05 to 0.23 ) or cause specific suicide rate (firearms: -0.46 suicides per 100000 adolescents per year, -1.96 to 1.04; non-firearms: -0.45 suicides per 100000 adolescents per year, -0.88 to 0.03 ) in West Virginia and Wyoming (which increased the minimum age of handgun purchase) relative to comparison states, the downward trend in suicide rates before the policy changes could suggest that any decline in suicide rates after these states increased the age for purchase of handguns was the result of a pre-existing downward trend in suicide rates.

In the difference-in-differences analysis, limiting the age of handgun purchase to those 21 years or older was associated with an average of 1.91 fewer suicides per 100000 adolescents aged 18 to 20 years $(-3.13$ to 


\begin{tabular}{|c|c|c|c|}
\hline Characteristics & Age 13-17 years & Age $18-20$ years & Pvalue \\
\hline \multicolumn{4}{|c|}{ Minimum age 18 for handgun sales ( $n=363946635$ in 34 states) } \\
\hline \multicolumn{4}{|c|}{ Race: } \\
\hline White & $175117772(77.5)$ & $106739756(77.4)$ & $<0.001$ \\
\hline Black & $38968541(17.2)$ & $23552489(17.1)$ & $<0.001$ \\
\hline Native American & $4399178(1.9)$ & $2595448(1.9)$ & $<0.001$ \\
\hline Asian/Pacific Islander & $7531743(3.3)$ & $5041708(3.7)$ & $<0.001$ \\
\hline Population density (people/square mile) & $34(89.4)$ & - & - \\
\hline Household firearm ownership (50 states) & $34(43.0)$ & - & - \\
\hline \multicolumn{4}{|c|}{ Minimum age 21 for handgun sales ( $n=190515326$ in 12 states) } \\
\hline \multicolumn{4}{|c|}{ Race: } \\
\hline White & $88745290(75.0)$ & $54220002(75.0)$ & $<0.001$ \\
\hline Black & $17228045(14.6)$ & $10197231(14.1)$ & $<0.001$ \\
\hline Native American & $1627432(1.4)$ & $1009453(1.4)$ & $<0.001$ \\
\hline Asian/Pacific Islander & $10648459(9.0)$ & $6839414(9.5)$ & $<0.001$ \\
\hline Population density (people/square mile) & $12(400.4)$ & - & - \\
\hline Household firearm ownership (50 states) & $12(24.1)$ & - & - \\
\hline
\end{tabular}

\section{Handgun sales period \\ - Age 18 \\ - Age 21}

States that changed the minimum purchaser age for handgun sales $(n=4)$, five years before and after policy changes

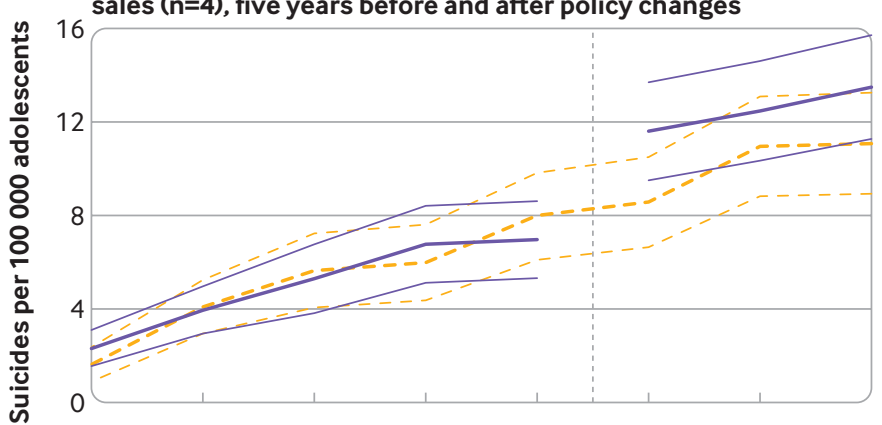

States that did not change the minimum purchaser age for handgun sales, 2001-17 $(n=46)$

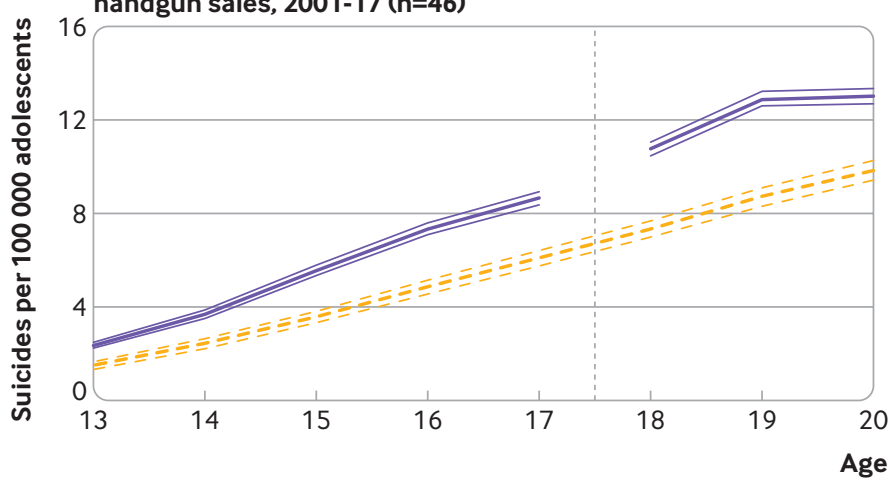

Fig 1 Suicide rate by age and minimum age of handgun purchase policy in states that changed policies and in states that did not change policies. Top panel: total suicide rate (with $95 \%$ confidence intervals) by age during the five years before and after policy changes (2002-06 and 2007-11 in Missouri; 2003-07 and 2008-12 in South Carolina; 2005-09 and 2010-14 in West Virginia and Wyoming). Missouri and South Carolina had a minimum handgun purchase age of 21 in the earlier periods and changed the minimum to age 18 in the later periods. West Virginia and Wyoming had a minimum handgun purchase age of 18 in earlier periods and changed the minimum to age 21 in later periods. Bottom panel: total suicide rate (with $95 \%$ confidence intervals) by age in states with age 21 and age 18 minimum handgun purchase age policies throughout 2001-17
-0.70 , permutation adjusted $\mathrm{P}=0.025$, table 4 ); this would be equivalent to an $18.1 \%$ reduction relative to a mean of 10.54 suicides per 100000 adolescents between 2002 and 2006. With 1220 suicide fatalities among adolescents aged 18 to 20 years in 2018 in the 33 states that did not have a minimum age of 21 years for handgun purchases by March 2020, an 18.1\% reduction would be equivalent to 221 (range 81-362) fewer suicides each year if all 33 states passed laws to limit the sale of handguns to those aged 21 or older. Policies limiting handgun purchases to people aged 21 or older were associated with a $35.5 \%$ reduction in firearm related suicides (-1.83 suicides per 100000 adolescents, -2.66 to -1.00 , permutation adjusted $\mathrm{P}=0.002$ ). No association was found between limiting the age of handgun sales to age 21 or older and nonfirearm related suicides (-0.08 suicides per 100000 adolescents, -0.70 to 0.54 , permutation adjusted $\mathrm{P}=0.771$ ).

In the heterogeneity analysis, there was not a statistically significant interaction between policies limiting handgun sales to those aged 21 or older and the direction of the policy change (increasing relative to decreasing) for total suicides ( -0.05 suicides per 100000 adolescents, -4.57 to 4.47 , appendix table 3 ) or firearm related suicides (0.71 suicides per 100000 adolescents, -2.37 to 3.79). However, the event study estimates depicted in figure 2 and the state specific estimates depicted in appendix figure 1 clearly show that the average difference-in-differences effect estimate was driven by an increase in the suicide rate in states that lowered the age that handguns could be purchased (Missouri and South Carolina) and no effect in the states that increased the age for handgun purchases (West Virginia and Wyoming).

Each of the difference-in-differences sensitivity analyses were consistent with the main results. The negative binomial regression analysis indicated that the total suicide rate decreased by $18 \%$ (incident rate ratio $0.82,95 \%$ confidence interval 0.75 to 0.90 , appendix table 3). In the falsification test among adolescents aged 13 to 17 , limiting the age for handgun purchases to age 21 or older was not associated with changes in the total suicide rate $(0.55$ suicides per 100000 adolescents, 95\% confidence interval -0.20 to 1.29 , appendix table 5) in this group who would not have been affected by policy changes. The synthetic control analyses were consistent with the event study estimates, indicating that reducing the age of handgun purchases from 21 to 18 years was associated with an estimated 42 more suicide deaths (average increase of 1.50 suicides per 100000 adolescents; standardized $\mathrm{P}<0.001$, appendix figure 2 parts (a) and (b) among adolescents aged 18 to 20 years in Missouri and South Carolina. Increasing the age from 18 to 21 years was not associated with a significant change in the suicide rate in West Virginia and Wyoming (standardized $\mathrm{P}=0.72$, appendix figure 2 parts (c) and (d)). Limiting the age of handgun purchases to age 21 or older were associated with suicides when including four years (-2.51 suicides per 100000 adolescents, -3.82 to 


\begin{tabular}{|c|c|}
\hline Variables & Incident rate ratio $(95 \% \mathrm{Cl})$ \\
\hline Treated (age 18-20 in states with age 18 limit on handgun sales, binary) & $1.26(1.10$ to 1.45$)$ \\
\hline Treated $\times$ continuous age & $1.09(1.03$ to 1.16$)$ \\
\hline Age (continuous) & 1.09 (1.04 to 1.14$)$ \\
\hline Age $^{2}$ (continuous) & $0.96(0.95$ to 0.97$)$ \\
\hline \multicolumn{2}{|c|}{$\begin{array}{l}\text { Estimates are based on negative binomial regression analyses with log population as an offset. Data are from all } \\
\text { states from } 1999 \text { to } 2017 \text { and are weighted based on state population size. Based on predicted probabilities, } \\
\text { an average of } 344 \text { suicides would have been averted in each state between } 2001 \text { and } 2017 \text { among adolescents } \\
\text { aged } 18 \text { to } 20 \text { years with policies restricting the minimum age of handgun sales to age } 21 \text { years relative to age } \\
18 \text { years. }\end{array}$} \\
\hline
\end{tabular}

-1.20 , appendix table 6) and six years ( -1.24 suicides per 100000 adolescents, -2.33 to -0.70 , appendix table 7) of data before and after policy changes.

\section{Discussion}

Suicide rates have been increasing in the US, particularly among adolescents. ${ }^{32}$ In two complementary analyses, we found that policies restricting the sale of handguns to those aged 21 or older were associated with a reduction in suicide rates among adolescents. In our regression discontinuity analysis of deviations in age trends among adolescents aged 18 to 20 years, policies that limited the sale of handguns to those aged 18 or older were associated with an absolute increase in suicides at age 18 years and an increase in the slope of age trends in suicide. In this analysis, we estimated an excess of 344 suicides among adolescents aged 18 to 20 years in each state with a minimum age of 18 years, relative to 21 years, for the purchase of handguns.

In our difference-in-differences analyses, policies restricting the sale of handguns to ages 21 or older were associated with 1.91 fewer suicides per 100000 adolescents aged 18 to 20 years, equivalent to an $18.1 \%$ relative reduction in the total suicide rate. Event study estimates revealed that the result was driven by increases in suicide rates in states that lowered the age for handgun purchases, with no effect in the states that increased the age. It is possible that the high levels of firearm ownership in Wyoming and West Virginia (66\% and 59\% of households in 2004, relative to 38\% in the 46 comparison states) meant that the change in age of handgun purchases had little effect on access to firearms by adolescents in these states.

The main result was robust to several sensitivity analyses varying the form of the regression, the time period of the study, and a synthetic comparison group. In cause specific analyses, there was a 35.5\% reduction in the firearm suicide rate, while there was no change in the non-firearm suicide rate.

Our findings that policies restricting the age of handgun purchases to age 21 or older are associated with a reduction in suicides among adolescents contribute to research indicating that restriction of the means of access, particularly to firearms, is associated with a reduction in suicides. ${ }^{6-8}$ Past research indicates that child access prevention laws requiring firearms to be stored in a locked location are associated with an $8 \%$ reduction in suicides among adolescents younger than 17 years. ${ }^{16}$ Our estimate of an $18 \%$ reduction in suicide is consistent with previous estimates of means restriction, which were associated with $10 \%$ to $34 \%$ reductions in suicide. ${ }^{33-35}$ As a rare outcome, suicide is difficult to study in randomized trials and in policy studies. Evidence on the efficacy of strategies to reduce suicide among adolescents, including antidepressants for those with depression, is mixed. ${ }^{36} 37$ Recent evidence suggests that policies raising the incomes of low wage workers are associated with a reduction in suicides, with a $10 \%$ increase in the earned income tax credit associated with a 5.5\% decline in suicides and a $10 \%$ increase in the minimum wage associated with a $3.6 \%$ decline in suicides. ${ }^{38}$

\section{Strengths and limitations of this study}

The strengths of this study include the use of data on the full population of adolescents in all US states and the complementary, rigorous analytical approaches. At the same time, this observational study is subject to several limitations. Suicide is a rare and a stigmatized outcome, and it is possible that deaths due to suicidal intent were underreported. ${ }^{39}$ Suicides might also be related to each other in ways that we could not detect in our analysis and which would not be fully captured by clustering standard errors by state. In the difference-indifferences study, spillover effects and the possibility that adolescents aged 18 to 20 years might cross state lines to purchase firearms in neighboring states with lower ages for handgun purchases could have led us to underestimate policy effects. We also could not control for unmeasured state characteristics that changed over time. Although state characteristics that do not change over time should not affect the difference-

\begin{tabular}{|c|c|c|c|}
\hline Characteristics & $\begin{array}{l}\text { Person years in intervention states } \\
(n=7197257)\end{array}$ & $\begin{array}{l}\text { Person years in } 46 \text { comparison states } \\
(n=161736784)\end{array}$ & $P$ value \\
\hline \multicolumn{4}{|l|}{ Race: } \\
\hline White & $5549361(77.1)$ & $123976436(76.7)$ & $<0.001$ \\
\hline Black & $1462380(20.3)$ & $26044785(16.1)$ & $<0.001$ \\
\hline Native American & $54867(0.8)$ & $2775827(1.7)$ & $<0.001$ \\
\hline Asian/Pacific Islander & $130649(1.8)$ & $8939736(5.5)$ & $<0.001$ \\
\hline Population density (people/square mile) & 76 & 170 & $<0.001$ \\
\hline Household firearm ownership (50 states) & 52.9 & 38.4 & $<0.001$ \\
\hline \multicolumn{4}{|c|}{$\begin{array}{l}1 \text { square mile }=2.6 \text { square kilometers. } \\
\text { West Virginia and Wyoming were outliers for some demographic characteristics. The population density in Wyoming was } 5 \text { per square mile. Household } \\
\text { firearm ownership was } 66 \% \text { in Wyoming and 59\% in West Virginia, whereas household firearm ownership was } 43 \% \text { in South Carolina and } 44 \% \text { in } \\
\text { Missouri. }\end{array}$} \\
\hline
\end{tabular}



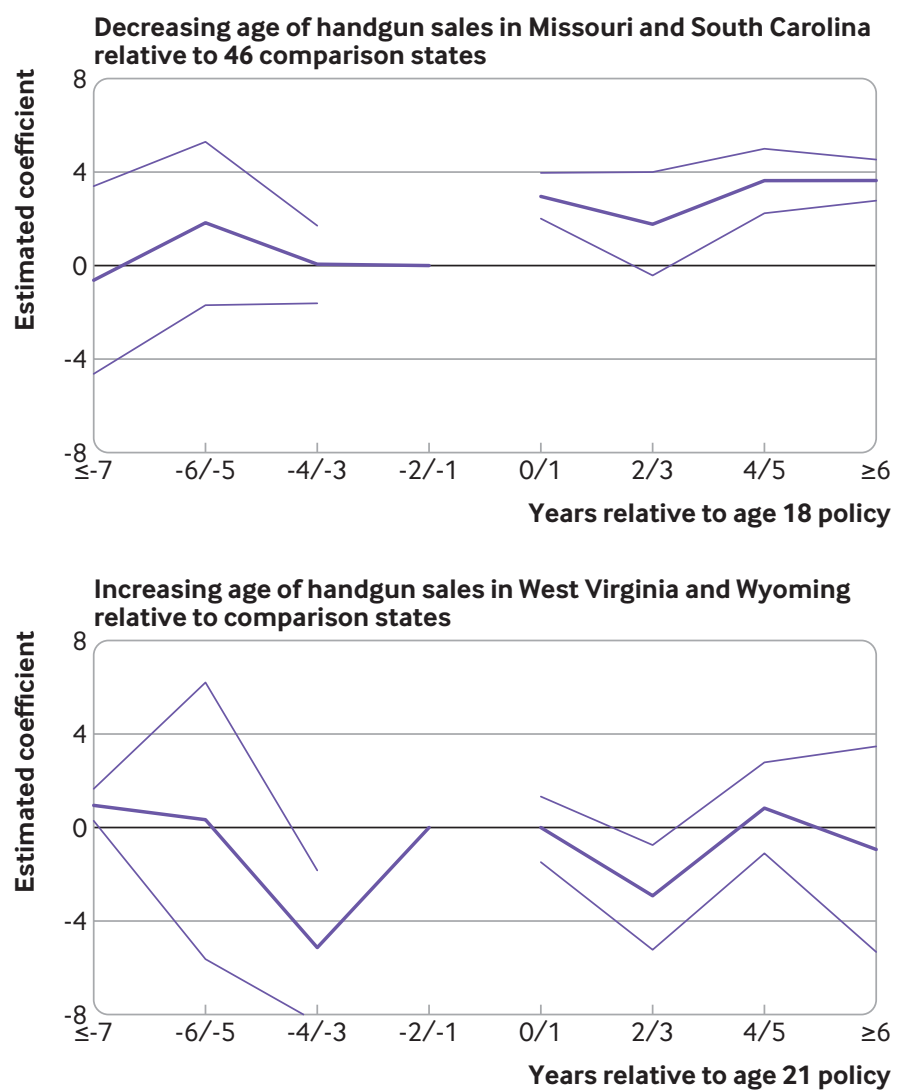

Fig 2 | Event study estimates of suicide rates among adolescents aged 18 to 20 years old. Coefficient estimates represent the estimated association between policy change and suicide rate in a given period relative to policy change. Estimated coefficients are based on running the main regression with all covariates, and the main policy variable replaced with binary indicators for years before or after policy changes in intervention states, with comparison states set to zero. Separate event studies were conducted for states that (top panel) decreased and (bottom panel) increased the minimum age of handgun purchase. Estimates were binned by two year periods because suicide is a rare event and individual year trends are volatile. The period immediately before the policy change was used as the reference period. The thin lines are $95 \%$ confidence intervals

in-differences analysis, differences existed between intervention and comparison states that could suggest different suicide mortality trajectories in these states. The generalizability of the difference-in-differences analyses is also limited. In such analyses we focused on just four states with policy changes. West Virginia and Wyoming passed the age 21 handgun sales policy and Missouri and South Carolina rescinded the age 21 handgun sales policy. The populations of each state differ substantially from those of the US population.

\section{Conclusion}

This study found that state policies setting the minimum age of handgun sales to 21 years, such as those passed in Florida and Vermont in 2018 and in Washington in 2019, were associated with a reduction in suicides among adolescents aged 18 to 20 years. In a regression discontinuity analysis, minimum age 18 handgun purchase policies were associated with an average 344 excess deaths from suicide among adolescents aged 18 to 20 years in each state between 2001 and 2017, relative to a minimum age of 21 handgun purchase policies. In a difference-indifferences analysis, restricting the age of handgun purchases to age 21 or older were associated with an $18 \%$ reduction in the suicide rate among adolescents, an effect estimate driven by increases in the suicide rate in Missouri and South Carolina after those states eliminated age 21 handgun sales policies. Changing the age of handgun sales policies from 18 to 21 years across the country or in the 33 states without such policies might reduce deaths from suicide among adolescents. Such a change is in keeping with public sentiment-in 2018, 67\% of American adults reported support for more policies regulating firearms. ${ }^{40}$

Contributors: JR conceived the study and drafted the manuscript. JR, EL, MS, MU, AK, CLB, and SG contributed to the acquisition, analysis, or interpretation of the data and to critical revision of the manuscript. JR and EL conducted the statistical analysis. MS obtained funding for the analysis. JR accepts full responsibility for the work as guarantor with full access to the data. The corresponding author attests that all listed authors meet authorship criteria and that no others meeting the criteria have been omitted.

Funding: This study was supported by the Robert Wood Johnson Foundation, Evidence for Action Program (grant \#73337). The funder played no role in the study.

Competing interests: All authors have completed the ICMJE uniform disclosure form at www.icmje.org/coi_disclosure.pdf and declare: MS reports grants from the Robert Wood Johnson Foundation, during the conduct of the study; no support from any organization for the submitted work; no financial relationships with any organizations that might have an interest in the submitted work in the previous three years; no other relationships or activities that could appear to have influenced the submitted work.

Ethical approval: Not required.

Data sharing: Data are publicly available from the National Vital Statistics System. Data analysis files are available from the corresponding author at jraifman@bu.edu.

\begin{tabular}{|c|c|c|c|}
\hline \multirow[b]{2}{*}{ Variables } & \multicolumn{3}{|c|}{ Suicide fatalities per 100000 adolescents $(95 \% \mathrm{Cl})$} \\
\hline & Total suicides & Firearm suicides & Non-firearm suicides \\
\hline Age 21 handgun sales & $-1.91 *(-3.13$ to -0.70$)$ & $-1.83+(-2.66$ to -1.00$)$ & $-0.08(-0.70$ to 0.54$)$ \\
\hline Per cent of firearm related suicides among ages $\geq 21$ years & $-8.99(-16.10$ to -1.88$)$ & $-3.88(-8.65$ to 0.89$)$ & $-5.11(-11.66$ to 1.44$)$ \\
\hline Population density & $0.02(-0.02$ to 0.06$)$ & $0.01(-0.02$ to 0.04$)$ & $0.01(-0.02$ to 0.04$)$ \\
\hline \multicolumn{4}{|l|}{ Per cent of population of each race/ethnicity: } \\
\hline Native American & $1.02(-0.84$ to 2.88$)$ & $-1.65(-3.22$ to -0.09$)$ & $2.68(1.18$ to 4.17$)$ \\
\hline White & $0.65(-0.22$ to 1.52$)$ & $0.14(-0.45$ to 0.74$)$ & $0.50(0.09$ to 0.92$)$ \\
\hline Other & Reference & & \\
\hline Handgun permit policy & $-0.69(-1.24$ to -0.14$)$ & $-0.48(-1.04$ to 0.08$)$ & $-0.21(-0.92$ to 0.51$)$ \\
\hline Universal background checks & $-0.23(-1.23$ to 0.77$)$ & $0.03(-0.42$ to 0.49$)$ & $-0.26(-1.26$ to 0.74$)$ \\
\hline
\end{tabular}


The manuscript's guarantor (JR) affirms that the manuscript is an honest, accurate, and transparent account of the study being reported; that no important aspects of the study have been omitted; and that any discrepancies from the study as planned have been explained.

Dissemination to participants and related patient and public communities: We will disseminate the research findings by creating a press release that summarizes the most important findings in the manuscript and links to the full manuscript. We will share the press release with media and with non-profit organizations focused on adolescent health, suicide prevention, and firearm injury prevention.

This is an Open Access article distributed in accordance with the Creative Commons Attribution Non Commercial (CC BY-NC 4.0) license, which permits others to distribute, remix, adapt, build upon this work non-commercially, and license their derivative works on different terms, provided the original work is properly cited and the use is noncommercial. See: http://creativecommons.org/licenses/by-nc/4.0/.

1 Centers for Disease Control and Prevention. Data Briefs - Number 328 - November 2018. 2018. https://www.cdc.gov/nchs/products/ databriefs/db328.htm (accessed 7 Dec 2018)

2 Centers for Disease Control and Prevention. 10 Leading Causes of Death by Age Group, United States - 2016. Atlanta, GA: 2016. https://www.cdc.gov/injury/images/lc-charts/leading_causes_of death_age_group_2016_1056w814h.gif

3 Centers for Disease Control and Prevention. WISQARS (Web-based Injury Statistics Query and Reporting System) Injury Center.

4 Parker K, Horowitz JM, Igielnik R, et al. America's complex relationship with guns. Pew Res. Center's Soc. Demogr. Trends Proj. 2017. https:// www.pewsocialtrends.org/2017/06/22/the-demographics-of-gunownership/ (accessed 6 Jun 2018).

5 Shenassa ED, Catlin SN, Buka SL. Lethality of firearms relative to other suicide methods: a population based study. J Epidemiol Community Health 2003:57:120-4. doi:10.1136/jech.57.2.120

6 Miller M, Barber C, White RA, Azrael D. Firearms and suicide in the United States: is risk independent of underlying suicidal behavior?Am J Epidemiol 2013;178:946-55. doi:10.1093/aje/kwt197

7 Miller M, Azrael D, Hepburn L, Hemenway D, Lippmann SJ. The association between changes in household firearm ownership and rates of suicide in the United States, 1981-2002. Inj Prev 2006:12:178-82. doi:10.1136/ip.2005.010850

8 Knopov A, Sherman RJ, Raifman JR, Larson E, Siegel MB. Household Gun Ownership and Youth Suicide Rates at the State Level, 2005-2015. Am J Prev Med 2019;56:335-42. doi:10.1016/j. amepre.2018.10.027

9 Wintemute GJ, Parham CA, Beaumont JJ, Wright M, Drake C. Mortality among recent purchasers of handguns. N Engl Med 1999;341:1583-9. doi:10.1056/NEJM199911183412106

10 Vermont General Assembly. S.55 (Act 94) An act relating to the disposition of unlawful and abandoned firearms. Vt. Legis. 2018. https://legislature.vermont.gov/bill/status/2018/S.55 (accessed 24 Oct 2018)

11 The Florida Senate. Senate Bill 7026: Public Safety. Fla. Senate. 2018. https://www.flsenate.gov/Session/Bill/2018/07026 (accessed 24 Oct 2018).

12 Chapter 9.41 RCW: FIREARMS AND DANGEROUS WEAPONS. https:// app.leg.wa.gov/RCW/default.aspx?cite=9.41 (accessed $20 \mathrm{Mar}$ 2020).

13 Public Law. Law 103-159. Brady Handgun Violence Prev Act 1993;18

14 Siegel M, Pahn M, Xuan Z, et al. Firearm-related laws in all 50 US states, 1991-2016. Am J Public Health 2017;107:1122-9. doi:10.2105/AJPH.2017.303701

15 U.S. Department of Justice. Do I need a license to buy and sell firearms? Washington, D.C.: 2016. https://www.atf.gov/file/100871/ download

16 Webster DW, Vernick JS, Zeoli AM, Manganello JA. Association between youth-focused firearm laws and youth suicides. JAMA 2004;292:594-601. doi:10.1001/jama.292.5.594

17 Giffords Law Center to Prevent Gun Violence. https://lawcenter. giffords.org/ (accessed 3 Mar 2020).

18 Sixtieth legislature of the state of Wyoming 2010 budget session. HB0095 - Wyoming Firearms Freedom Act-2. https://www.wyoleg. gov/Legislation/2010/HB0095 (accessed 10 Feb 2020).
19 Moscoe E, Bor J, Bärnighausen T. Regression discontinuity designs are underutilized in medicine, epidemiology, and public health: a review of current and best practice. / Clin Epidemiol 2015;68:122 33. doi:10.1016/j.jclinepi.2014.06.021

20 Bor J, Moscoe E, Mutevedzi P, Newell ML, Bärnighausen T. Regression discontinuity designs in epidemiology: causal inference without randomized trials. Epidemiology 2014;25:729-37. doi:10.1097/ EDE.0000000000000138

21 Dimick JB, Ryan AM. Methods for evaluating changes in health care policy: the difference-in-differences approach. JAMA 2014;312:2401-2. doi:10.1001/jama.2014.16153

22 Wooldridge J. Econometric Analysis of Cross Section and Panel Data. MIT Press, 2010. https://mitpress.mit.edu/books/econometricanalysis-cross-section-and-panel-data-second-edition accessed 29 June 2020.

23 Goodman-Bacon A. Difference-in-differences with variation in treatment timing. NBER Working Paper No 25018. Issued in September 2018.

24 Venkataramani AS, Cook E, O’Brien RL, Kawachi I, Jena AB, Tsai AC. College affirmative action bans and smoking and alcohol use among underrepresented minority adolescents in the United States: A difference-in-differences study. PLoS Med 2019;16:e1002821. https://doi.org/10.1371/journal.pmed.1002821

25 Greene W. The behaviour of the maximum likelihood estimator of limited dependent variable models in the presence of fixed effects. Econom / 2004;7:98-119. doi:10.1111/j.1368-423X.2004.00123.x

26 Sen B, Panjamapirom A. State background checks for gun purchase and firearm deaths: an exploratory study. Prev Med 2012;55:34650. doi:10.1016/j.ypmed.2012.07.019

27 Sumner SA, Layde PM, Guse CE. Firearm death rates and association with level of firearm purchase background check. Am J Prev Med 2008;35:1-6. doi:10.1016/j.amepre.2008.03.023

28 Crifasi CK, Meyers JS, Vernick JS, Webster DW. Effects of changes in permit-to-purchase handgun laws in Connecticut and Missour on suicide rates. Prev Med 2015;79:43-9. doi:10.1016/j. ypmed.2015.07.013.

29 Bertrand M, Duflo E, Mullainathan S. How much should we trust differences-in-differences estimates? National Bureau of Economic Research 2002. http://www.nber.org.ezp-prod1.hul.harvard.edu/ papers/w8841 (accessed 4 May 2016)

30 Rokicki S, Cohen J, Fink G, et al. Inference With Difference-inDifferences With a Small Number of Groups: A Review, Simulation Study, and Empirical Application Using SHARE Data. Med Care 2017 56:97-105. doi:10.1097/MLR.0000000000000830.

31 Rudolph KE, Stuart EA, Vernick JS, Webster DW. Association between Connecticut's permit-to-purchase handgun law and homicides. Am J Public Health 2015;105:e49-54. doi:10.2105/AJPH.2015.302703

32 Stone DM, Simon TR, Fowler KA, et al. Vital Signs: Trends in State Suicide Rates - United States, 1999-2016 and Circumstances Contributing to Suicide - 27 States, 2015. MMWR Morb Mortal Wkly Rep 2018;67:617-24. doi:10.15585/mmwr.mm6722a1.

33 Kreitman N. The coal gas story. United Kingdom suicide rates, 196071. BrJ Prev Soc Med 1976;30:86-93. doi:10.1136/jech.30.2.86.

34 Myung W, Lee G-H, Won H-H, et al. Paraquat prohibition and change in the suicide rate and methods in South Korea. PLOS One 2015;10:e0128980. doi:10.1371/journal.pone.0128980

35 Gunnell D, Fernando R, Hewagama M, Priyangika WD, Konradsen F, Eddleston M. The impact of pesticide regulations on suicide in Sri Lanka. Int J Epidemiol 2007;36:1235-42. doi:10.1093/ije/dym164.

36 Jane Garland E, Kutcher S, Virani A, Elbe D. Update on the Use of SSRIs and SNRIs with Children and Adolescents in Clinical Practice. J Can Acad Child Adolesc Psychiatry 2016;25:4-10

37 Zalsman G, Hawton K, Wasserman D, et al. Suicide prevention strategies revisited: 10 -year systematic review. Lancet Psychiatry 2016;3:646-59. doi:10.1016/S2215-0366(16)30030-X

38 Dow WH, Godøy A, Lowenstein CA, et al. Can Economic Policies Reduce Deaths of Despair? National Bureau of Economic Research, 2019, 10.3386/w25787

39 Gosney H, Hawton K. Inquest verdicts: youth suicides lost. Psychiatrist 2007;31:203-5.

40 Gallup. Guns. Gallup.com. https://news.gallup.com/poll/1645/Guns. aspx (accessed 23 Jul 2018).

Supplemental information: equations and additional tables and figures 